DIGITALCOMMONS

@WAYNESTATE-
Michigan Journal of Counseling:

Research, Theory and Practice

Volume 33 | Issue 1

Article 4

8-1-2005

\title{
The Influence of Demographic Information, Ethnic Identity, and Pro-Feminist Attitudes on Cognitive Empathy
}

Robbie J. Steward

Michigan State University

Robin Powers

Gannon University

Hanik Jo

Hanyang University

Follow this and additional works at: https://digitalcommons.wayne.edu/mijoc

\section{Recommended Citation}

Steward, R. J., Powers, R., \& Jo, H. (2005). The Influence of Demographic Information, Ethnic Identity, and Pro-Feminist Attitudes on Cognitive Empathy, Dimensions of Counseling, 33(1), 17-30. doi:10.22237/mijoc/1122854580

This Article is brought to you for free and open access by the Open Access Journals at DigitalCommons@WayneState. It has been accepted for inclusion in Michigan Journal of Counseling: Research, Theory and Practice by an authorized editor of DigitalCommons@WayneState. 


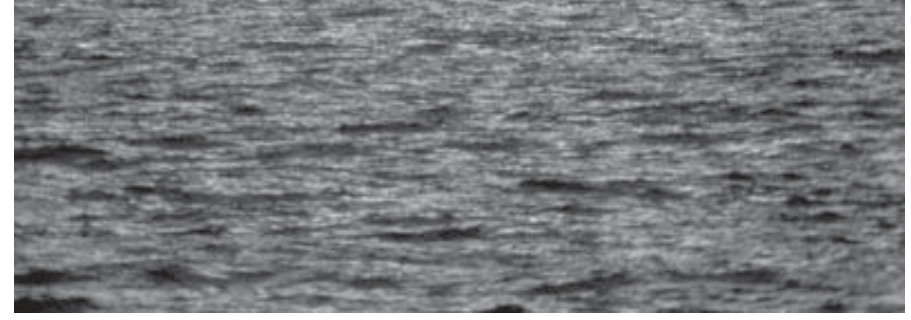

\section{The Influence of Demographic Information, Ethnic Identity, and Pro-Feminist Attitudes on Cognitive Empathy}

Robbie J. Steward, Ph.D.

Michigan State University

Robin Powers, Ph.D.

Gannon University, Erie, PA

Hanik Jo, Ph.D.

Hanyang University, South Korea
A critical overview of the literature provides a frame for the overall purpose of this empirical study, which examines the influence of ethnic identity and attitudes about women on individuals' ability to engage in empathic thinking. Results of a hierarchical multiple regression analysis indicated that undergraduate students' (n=179) ethnic identity and attitudes about women significantly contributed to $23 \%$ of the variance in the ability to think empathically. Among the three sets of independent variables (demographic information, attitudes about women, and ethnic identity subscales), ethnic identity was found to be the only significant ( $p<$ .01) contributor to the model, explaining $17 \%$ of the $23 \%$ variance in scores measuring ability to use empathy. Findings suggested that individuals who scored higher on the ethnic identity scale, particularly in relationship to the orientation to other groups, had a greater ability to think empathically, as indicated by higher scores on the empathy scale. Implications for training in counseling programs is discussed.

n the general literature of psychology and counseling, the construct of empathy is defined as the ability and willingness to examine one's impact on others, and to commit to the improvement of self and others (Carkhuff, 1987; Egan, 1990; Rogers, 1942; Weitz, 1957). Leaders in character development education purport empathy as an underlying reinforcer of values, attitudes, and behaviors associated with responsibility, honesty, integrity, respect, living peaceably, caring, and civility within the general populace (The Josephson Institute of Ethics, 1992, 2002; Leonard, 1997). Within the general social science 
literature, it is considered to be a critical component of civic identity and citizenship within a democracy (i.e., recognition of one's social and legal link to other individuals within society) (Patrick, 1999). Empathy has been found to be significantly and empirically correlated with many positive qualities that benefit the overall, larger social structure: altruism (Jegerski \& Upshaw, 1987; Oswald, 1996), ethical-decision making (Foltz, Kirby, \& Paradise, 1989), pro-social behaviors, such as nurturance, succorance, and a just orientation (Hoffman, 2000), higher cognitive functioning and cognitive complexity, and social responsibility (Jegerski \& Upshaw, 1987; Roberts \& Strayer, 1996). The absence of empathy has been linked to both intergroup aggression (Struch \& Schwartz, 1989) and social dominance orientation (Pratto, Sidanium, Stallworth, \& Malle, 1994).

The construct of empathy has a unique and important position within the professions of Counseling, Counseling Psychology, and other helping professions. First, practitioners use the ability to engage in empathic thinking as a benchmark in the assessment and diagnosis of character or personality disorders. For example, the Diagnostic and Statistical Manual of Mental Disorders (or DSM; axis 2 diagnoses in the third and fourth editions; American Psychiatric Association, 1987) makes reference to complete self-absorption and the absence of empathy or empathy related behaviors as an indicator of psychosocio-emotional maladaption (i.e., Narcissistic Personality Disorder, Conduct Disorder, Antisocial Personality Disorder, Avoidant Personality Disorder). The ability to empathize with others has been deemed critical to all human relationships (Omdahl, 1995) and "an essential constituent" (Kohut, 1959, as cited in Duan \& Hill, 1996, p. 262) of all psychological phenomenon.

Second, organizational psychologists have recognized the importance of attending to the influence of empathyrelated behaviors and thinking (i.e., responsibility, ethics, caring, fairness) in organizational functioning and productivity (Leonard, 1997; Levinson, 1997; Kilburg, 1997). Consultants also recognize the importance of the assessment of empathic expression as a means of better understanding issues within human systems in the world of work.

Third, the longstanding and persisting empirical and conceptual link between counselors' ability to empathize and effective counseling and psychotherapy found within the literature (Chung \& Bemak, 2002; Duan \& Hill, 1996; Farber \& Lane, 2001; Fuertes \& Brobst, 2002; Gladstein, 1983; Greenberg, Watson, Elliot, \& Bohart, 2001; Lambert \& Barley, 2001; Orange, 2002; Scott \& Borodovsky, 1990) certainly serves as a powerful influence in curriculum development, counseling supervision, and service delivery. More specifically, it has been empirically correlated with the construct, universal-diverse orientation, which reflects an attitude of awareness and acceptance of both the similarities and differences among people (Mivelle, Gelso, Pannu, Liu, Touradji, Holloway, \& Fuertes, 1999).

In appreciation and recognition of the power of the effective expression of empathy, both the American Counseling Association Code of Ethics and Division 17 (Counseling Psychology) of the American Psychological Association (APA) have included in mission statements a mandated commitment for professionals to express empathy (i.e., respect and value) to all individuals within society, particularly those who typically are not recipients of such within mainstream society due to racial/ethnic minority status, gender, sexual orientation, and socioeconomic status. In addition, the APA has developed specific guidelines on multicultural education, training, research, and organizational change for all psychologists (American Psychological Association, 2003).

Pedersen (1990), a leading scholar in psychology, identified sensitivity to issues of diversity within training and practice as a "Fourth Force" within Counseling Psychology. Subsequently, terms such as cultural empathy (Ridley \& Lingle, 1996, p.32; Ridley \& Udipi, 2002, p. 322), ethnocultural empathy (Wang, Davidson, Yakushko, Savoy, Tan, \& Bleier, 2003), empathetic multicultural awareness (Junn, Grier, \& Behrens, 2001), cultural role-taking (Scott \& Borodovsky, 1990), ethnic perspective taking (Quintana, CastaÒeda-English, \& Ybarra, 1999) and ethnotherapeutic empathy (Parson, 1993) have appeared and used interchangeably in the literature to specifically address the concept of empathy in multicultural settings (Wang, et al., 2003). Practitioners and researchers within the multicultural movement have assumed that the basic construct of empathy, which has long been embraced within counseling, is no longer sufficient or applicable in cross-cultural interactions and the development of new constructs is warranted, along with the development of appropriate measures.

In light of very limited empirical support, others within the profession question and challenge the multicultural movement, which tends to highlight the limitations of 'old ways and practices' (Thomas \& Weinrach, 2004; Weinrach \& Thomas, 2004; Thomas \& Weinrach, 2002(a); Thomas \& Weinrach, 2002(b); Thomas \& Weinrach, 1999; Weinrach \& Thomas, 1998). These leaders in the field perceive the new terms and the development of the associated multicultural competencies as premature and without any substantial empirical support (Weinrach \& Thomas, 2002). This means that those who are multiculturally self-aware and culturally knowledgeable may not be any more competent in expressing empathy than those who are not. A healthy challenge and dialogue between members of the two positions have ensued, and more focused research specifically examining the 
relationship between the old and new constructs has been strongly recommended and encouraged. This study is one effort to examine the primary question raised in the continued dialogue between the two perspectives within the profession.

In summary, the pervasive influence of empathy, past and present, is wellestablished in literature, in education, in training, and in practice. A shifting social zeitgeist and an increase in diversity within the general populace, and the profession, have fueled a plethora of empirical research re-examining the construct of empathy and empathy development. It would seem critical that we, as practitioners and researchers in the counseling profession should more clearly identify the significant influences in individuals' development of empathic thinking and expression. Doing so would allow us to more effectively conceptualize and facilitate the development of empathy within the general population and among those who receive our services, to potentially better understand the factors that contribute to the readiness for training, and to hone curriculum that will eventually lead to the most effective service delivery to client populations regardless of race, culture, or gender. The following section provides a brief overview of the literature, addressing the relationship between the ability to empathize and attitudes related to the two most predominant and widely attended to points of diversity within counseling and counseling psychology: ethnic identity and gender.

\section{Ethnic Identity}

Ethnic identity influences ways in which individuals conduct their lives, interact with people from other groups, and view society as a whole (Phinney, 1996a). It is a complex construct that involves self-identification as a group member, attitudes and evaluations in relation to one's group, attitudes about oneself as a group member, extent of ethnic knowledge and commitment, and ethnic behaviors and practices (Phinney, 1992). Social identity theory (SIT) proposes that the more strongly one identifies with their group of identity, the less favorable attitudes they have toward dissimilar groups (Tajfel, 1986). Researchers have found that individuals tend to be least empathic in interactions with those who differ from them in race, ethnicity, and culture, for Whites and
Hispanics (Negy, Streve, Jensen, \& Uddin, 2003); for Whites, Blacks, and Asians (Tzeng \& Jackson, 1994); Chinese and Blacks (Lee, 1995). Those who are able to engage in empathic thinking with members of their own group have been found to be significantly less competent in doing so with members of other groups. This phenomenon has proven to be quite resistant to change without strategic intervention (Brewer, 1988; Hamilton \& Trolier, 1986).

Interventions designed to enhance empathy, specifically related to points of difference, have been noted by some as the primary source of hope in bridging the rift that exists between the ability to empathize with members of one's own group and the ability to empathize with an out-group or stigmatized group member (Batson, Polycarpou,, Harmon-Jones, Imhoff, Mitchener, Bednar, Klein, \& Highberger, 1997). Findings from these studies support the notion that an individual's ability to express empathy to those outside their group of identity is a distinctly different construct from their basic ability to empathize in general (Wang et al., 2003).

In contrast to the social identity theory, multicultural theory (Phinney, Ferguson, \& Tate, 1997), which purports that high ethnic identity is the ideal state of development, proposes that an individual's affirmation toward his or her group, particularly with respect to culture, race, and ethnicity, should correspond with higher levels of acceptance toward outside group members (Berry, 1984; Helms, 1984; Messick \& Mackie, 1989; Phinney, 1996b). Phinney, Ferguson, and Tate (1997) found supporting empirical evidence for this theory in a study of adolescents and, in the face of questions and challenge, recommendations for future research in support of this theory continue to exist in the literature (Penn, Gaines, \& Phillips, 1993).

\section{Gender and Liberal Feminism}

As noted above in the discussion of the mandated respect and attention to race and ethnicity within practice and policies of both the ACA and the APA, respect for issues of gender is deeply ingrained within the professions of Counseling and Counseling Psychology. As the gender composition within psychology has shifted to a majority 
female population (American Psychological Association, 1995; Boatswain, Brown, Fiksenbaum, Goldstein, Geenglass, Nadler, \& Pyke, 2001; Ostertag \& McNamara, 1991), feminist philosophy, which first appeared in the discipline over the last three decades, has also become increasingly integrated within the profession, mainstream training, curriculum, and practice (Boatswain, Brown, Fiksenbaum, Goldstein, Geenglass, Nadler, \& Pyke, 2001; Enns, 1992; Enns \& Hackett, 1990; Fischer \& Good, 1994; Janz \& Pyke, 2000; Szymanski, Baird \& Kornman, 2002; Worell \& Remer, 2003). Liberal or mainstream feminism, the focus of this study, evolved in response to the subordination of women in legal, economic, and cultural constraints that blocked access to opportunities available to men. This philosophy advocates ideals of human dignity, equality, self-fulfillment, autonomy, and rationality. Proponents' primary objectives include the reformation of existing legal and political systems that limit individual freedom and the removal of oppression resulting from rigid sex-role conditioning and irrational prejudices (Enns, 1992). The influence of women's increased presence upon the fields of both Counseling and Counseling Psychology appears to be quite evident.

However, the influence of the profession's strong adherence to a pro-feminist perspective seemingly extends beyond professional policy, training, and service delivery to the arena of empirical research as well. Reid (2002) purported that the inclusion of gender as a major descriptor in sample populations is as essential as the identification of ethnicity, social class, religion, sexuality, or family background. However, the multicultural literature has been found to ignore issues of gender and the impact of sexism (Jones, 1991; Gilbert \& Scher, 1999; Glick \& Fiske, 1999). The direct association between adherence to liberal feminist attitudes and the ability to think empathically within the general population remains relatively unexamined.

The purpose of this study is to examine the degree to which ethnic identity and adherence to pro-feminist attitudes predicts individuals' intellectual or cognitive empathy, the ability to cognitively experience another's state. Because a significant relationship has consistently been found between affective or expressive and cognitive or intellectual empathy (Duan \& Hill, 1996), the focus of this study will be what has been considered the necessary precursor to affective or expressed empathy: intellectual or cognitive empathy. One must be able to think in an empathic manner prior to effectively expressing empathy to another. The independent variables, sense of self as a member of an ethnic group in this country, and commitment to liberal feminist thought, were specifically chosen given that these are the training interventions that are most typically visible and strongly recommended in efforts to decrease stereotypical thinking and increase trainees' self and other awareness, knowledge, and interpersonal skill (Broverman, Broverman, Clarkson, Rosenkrantz, \& Vogel, 1970; Okun, 1987).

In addition, as stated above, issues of ethnicity and gender are components of one of the most recent forces in Counseling and Counseling Psychology. As recommended in the multicultural literature (Arredondo et al, 1996; Munley et al, 2002), demographic variables were relating to age, gender, culture, ethnicity, race, social class were included in this model, as were the variables of educational background and income. Undergraduate students who had not been exposed to graduate training in counseling or empathic thinking were chosen for participation in this study, in order to address the impact of students' awareness of and sensitivity to ethnicity and gender. The authors assumed that an undergraduate population would not be as influenced by a press to respond with 'political correctness' as graduate level counseling student populations, and consequently, more accurate reports of attitudes about race and gender would occur.

\section{Method}

\section{Participants}

Participants were students enrolled in a small university located in the Southern Region. The student population of this university is 5,746 with a $14 \%$ African American representation. Twenty percent of the undergraduate population is 25 years or older. The surveys were distributed to 180 students who were enrolled in undergraduate courses in psychology during the fall semester of the academic year. Of the 179 students who completed survey packets, $141(78.8 \%)$ self-identified as White American and $38(21.3 \%)$ self-identified as African American; 134 (74.9\%) female and $45(25.1 \%)$ male.

The mean age of the sample was 20.35 years $(S D=4.31$, range $=18-48$ ). The modal age was 21 years, and approximately $70 \%$ of the sample fell in the age range of 19 to 25 . The distribution of the sample with regard to year in school was somewhat skewed with $92 \%$ being either freshmen or sophomores. The mean annual income for participants' families of origin was $\$ 55,806$ ( $S D=$ $\$ 35,601$, range $=\$ 9,000-\$ 250,000)$.

\section{Procedure}

Participants were asked to respond to three questionnaires, which were distributed together in individual survey packets to students who signed and returned consent for participation in research. All identifying information was removed from numbered survey packets that were maintained in a locked file cabinet. 


\section{Measures}

The 115-item Scale of Intellectual Development (SID) (Erwin, 1982) was chosen as the measure of cognitive complexity in this study. The SID, based on Perry's scheme of intellectual and ethical development (1970), was designed to measure the construct of cognitive development or complexity. Each survey item is presented as a four-point Likert scale ranging from strongly disagree (4) to strongly agree (1). Scoring results in four scores related to each of the following subscales: Dualism, relativism, commitment, and empathy. Each subscale describes a particular cognitive "form" in which individuals construe the diversity of the world around them. For the purpose of this study, only the scores on the subscale assessing the highest level of cognitive development, empathy (Stage IV), were included as the dependent variable. The empathy (Stage IV) subscale items measure the extent to which individuals are aware of their impact on other people. Those scoring high on this scale have developed a sensitivity about other people and feel responsibility for improving society in general. This subscale purports to assess ability to empathize, which has been consistently identified as a critical component in counseling training, as well as counseling process (Brammer, Shostrom, \& Abrego, 1989; Egan, 1990; Hammer, 1983). This is the only subscale score that will be used in the data analyses, as it is the focus of this study.

Coefficient alpha reliability for this stage is .73. Evidence for construct validity of the scales designed to measure Chickering's vector of identity has been found in Erwin and Delworth (1980), Erwin and Schmidt (1981), and Erwin (1981).

The Multigroup Ethnic Identity Measure (MEIM: Phinney, 1992) was developed to assess ethnic identity attitudes among diverse minority groups. The MEIM consists of 14 items measuring three aspects of ethnic identity: (a) Affirmation/belonging (five items); (b) ethnic identity achievement, including both exploration and resolution of identity issues (seven items); and (c) ethnic behaviors (two items). Item responses are obtained using a four-point Likert scale ranging from (4) strongly agree to (1) strongly disagree. An additional six items are included in the questionnaire to assess other-group orientation.

Reliability coefficients (Cronbach's Alphas) were reported for the MEIM and two of its subscales. Phinney (1992) found that overall reliability of the measure was .81 for the 417 high school students and .90 for the 136 college students. For the fiveitem affirmation/belonging subscale, reliabilities were .75 for the 417 high school students and .86 for the 136 college students. For the seven-item ethnic identity achievement subscale, reliabilities were .69 for the 417 high school students and .80 for the 136 college students. Reliability was not calculated for the subscale of ethnic behaviors because it has only two items. For the separate other-group orientation, reliabilities were .71 for the high school students and .74 for the college students. In a study of 12 studies incorporating the MEIM, Ponterotto, Gretchen, Utsey, Stracuzzi, \& Saya (2003) found ethnic identity and other-group orientation to be relatively distinct, have satisfactory levels of internal consistency, and have moderate degrees of construct and criterion-related validity.

The short form of the Attitudes toward Women Scale (ATW; Spence, Helmreich, \& Stapp, 1973) consists of 25 Likert-type items that assess the degree to which individuals adopt liberal or pro-feminist views of women's roles. This short form is developed from a 50-item longer form version (Spence \& Helmreich, 1972). Item responses are obtained using a four-point scale ranging from (A) strongly agree to (D) strongly disagree. Sample item stems are: (a) It is insulting to women to have the "obey" clause remain in the marriage service; (b) Women should take increasing responsibility for leadership involving the intellectual and social problems of the day; (c) Women should worry less about their rights and more about becoming good wives and mothers; and (d) Women should be given equal opportunity with men for apprenticeship in the various trades. Higher scores on this scale are interpreted as a greater adherence to pro-feminist consciousness, whereas lower scores indicate more conservative views toward the roles of women in general society.

There has been positive evidence of construct validity, criterion validity, and reliability. An administration of the scale to 258 female and 293 male university students yielded only one major factor, accounting for $23 \%$ and $30 \%$ of the total variance, respectively. Separate reliability analyses over female and male participants yielded alphas of .90 for the short form. A person correlation between the short and long forms produced a coefficient of .99 (Smith \& Bradley, 1980). Relationships between ATW scores and the Sex-Role Egalitarianism Scale (King \& King, 1997), the Personal Attributes Questionnaire (Spence, Helmreich, \& Stapp, 1974) and the MacDonald 
Sex Role Survey (MacDonald, 1974), other measures of attitudes toward the equality of men and women, support convergent, discriminant, and construct validity (Carter, 1990; Honeck, 1981; Jaffa, 1985).

\section{Results}

Means and standard deviations were computed for each of the primary variables and Pearson product correlation analysis results are presented in Table 1 . A positive and significant correlation was found between participants' age and adherence to pro-feminist attitudes $(\mathrm{r}=.16 ; p<$ $.05)$. This correlation indicated that older individuals within the sample, which included an age range of 18-48, tended to adhere more strongly to pro-feminist attitudes than younger participants. This was the only significant correlation found between the sets of independent variables. All of the correlations between the independent variables of ethnic identity, attitudes about women, and demographic information were low to moderate. These results reduced the possibility of having to address the potential problem of multi-collinearity in the primary analyses.

Table one presents the means and standard deviations by gender and race. To determine whether men and women differed significantly in their scores on the primary variables, $t$ tests were performed. Because of the decision to use multiple $t$-tests, the Bonferoni adjustment to the significance level was used to ensure the significance level for the tests as a group was at the .05 level. The resulting level of significance was $.025(.05 / 2)$. A significant gender difference was found on the dependent variable of empathy. Women had a significantly higher total SID Empathy subscale score than did men, $t(179)=$ $2.1, p<.05$. The results mean that, in general, the women in this study are more aware of their impact on other people, have greater sensitivity about others, and feel responsible for improving society more so than men do. In addition, women tended to have more liberal and positive attitudes about women than men, $t(179)=3.72$, $p<.05$.

To determine racial differences on the primary variables, $t$ tests were also performed. Significant differences were found between the two groups on several variables.

Annual family incomes for white participants within this sample were significantly higher than those of African American participants within this sample, $t(179)=4.41$, $p<.05$. In addition, white participants had significantly higher empathy scores than African American participants, $t(179)=2.22, p<.05$. These results mean that, in general, white participants had more affluent family backgrounds and were more aware of their impact on other people, had greater sensitivity about others, and felt responsibility for improving society more so than African American participants did. In addition, African American
Table 1.
Means, Standard Deviations and Range for Black Females (BF) Black Males (BM), White Females (WF), and WhiteMales (WM)

\begin{tabular}{lcccc}
\hline Variables & BF & BM & WF & WM \\
\hline 1. Age & & & & \\
Mean & 18.90 & 20.4 & 20.39 & 20.79 \\
SD & 4.22 & 2.06 & 4.84 & 4.18 \\
Range & $18-28$ & $18-24$ & $18-48$ & $18-41$ \\
$N$ & 31 & 5 & 101 & 39 \\
\hline 2. Income & & & & \\
Mean & 23103 & 46000 & 39294 & 64012 \\
SD & 24174 & 26522 & 40869 & 38212 \\
Range & $\$ 9000-85000$ & $\$ 40000-80000$ & $\$ 12000-250000$ & $\$ 15000-170000$ \\
$N$ & 22 & 4 & 70 & 38 \\
N & & & & \\
3. Ethnicldentity Total & 3.46 & 3.43 & 2.99 & 2.98 \\
Mean & .41 & .63 & .47 & .49 \\
SD & $.07-4.0$ & $2.42-4.0$ & $1.5-3.86$ & $2.07-3.86$ \\
Range & 2.06 & 30 & \\
N 32 & 5 & 101 & & \\
\hline 4. Attitudes about Women & & & \\
Mean & 60.39 & 57.60 & 58.06 & 50.90 \\
SD & 6.45 & 9.50 & 9.65 & 12.53 \\
Range & $47-71$ & $41-62$ & $28-75$ & $22-71$ \\
N & 39 & 39 & 39 & 39 \\
\hline
\end{tabular}

students' responses indicated significantly more liberal and positive attitudes about women than did white American participants, $t(179)=2.91, p<.05$, and also had an overall stronger ethnic identity than white American participants $t(179)=5.35, p<.05$. No other significant differences were found based upon race and gender. However, these significant $t$ test results led to the decision to include gender, race, and socio-economic background as predictor variables in the regression analysis. Given the developmental nature of ethnic identity and cognitive thinking, age was included in the regression analysis as well. Evidence that both constructs are age-dependent has been found in the literature. Individuals' ethnic identity scores and cognitive thinking scores have both been found to increase with age (Phinney, 1992; Brammer, Shostrom, \& Abrego, 1989).

On the measure for pro-feminist attitudes, white men scored lowest $($ mean $=50.90)$; black women scored highest $($ mean $=60.39)$; and black men's scores $($ mean $=$ $57.60)$ and White women's scores (mean $=58.06)$ were most similar. On the empathy scale, black men scored the lowest (mean $=42.13)$; white women scored the highest $($ mean $=60.10)$; black women's scores $($ mean $=54.65)$ and 
Table 2.

\section{Means, standard deviations, range, and Pearson product correlations between each pair of variables.}

\begin{tabular}{|c|c|c|c|c|}
\hline Variable & 1 & 2 & 3 & 4 \\
\hline $\begin{array}{l}\text { 1. Age } \\
\begin{aligned} \text { Mean } & =20.35 \\
S D & =4.31 \\
\text { Range } & =18-48\end{aligned}\end{array}$ & & $r=-.03$ & $r=-.05$ & $r=.16$ * \\
\hline $\begin{array}{l}\text { 2. Income } \\
\qquad \begin{array}{l}\text { Mean }=\$ 55806 \\
\mathrm{SD}=\$ 35601\end{array} \\
\text { Range }=\$ 9000-\$ 250000\end{array}$ & & & $r=.08$ & $r=-.14$ \\
\hline $\begin{array}{l}\text { 3. Ethnic } \\
\text { Identity Total } \\
\text { Mean }=3.21 \\
\text { SD }=.48 \\
\text { Range }=1.64-4.00\end{array}$ & & & & $r=.02$ \\
\hline $\begin{array}{l}\text { 4. Attitudes about } \\
\text { Women } \\
\text { Mean }=56.73 \\
\text { SD }=10.45 \\
\text { Range }=22 \cdot 75\end{array}$ & & & & 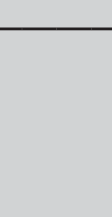 \\
\hline
\end{tabular}

white men's scores $($ mean $=54.51)$ were most similar. Statistical analysis to compare these differences were not performed due to the vast differences in representation of these subgroups within the sample. Therefore, though these patterns are interesting, future research specifically addressing race and gender is strongly recommended.

Table 2 presents the means and standard deviations of the primary variables and Pearson product correlation analysis results for the overall sample. A positive and significant correlation was found between participants' age and adherence to pro-feminist attitudes $\left(r=.16^{\prime} p<\right.$ .05 . Older individuals tended to adhere more strongly to pro-feminist attitudes than younger participants. This was the only significant correlation found between the sets of independent variables. All of the correlations between the independent variables of ethnic identity, attitudes towards women, and demographic information were low to moderate. These results reduced the possibility of having to address the potential problem of multi-collinearity in the primary analysis.

Table 3 presents the Pearson product correlations between each set of the standardized measure scores in the model. Significant correlations were found between empathy and the ethnic identity total scores $(r=.15)$, ethnic identity achievement $(\mathrm{r}=.16)$; ethnic identity behavior $(\mathrm{r}=.12)$, and ethnic identity other $(r=.19)$. Attitudes toward Women Scale scores were found to be significantly correlated only with ethnic identity other group orientation $(\mathrm{r}=.26)$.

A multiple regression analysis procedure was used to assess the degree of impact that each of the independent variables had on the dependent variable of empathy. A hierarchical regression analysis was conducted with demographic variables, ethnic identity, and attitudes about women as the predictors for the total SID empathy subscale score (Table 4). Age, family income, racial status, and gender were entered in the first block because these are primary demographic variables. Ethnic identity was entered in the second block before the other predictor variables because of previous research findings that identified a significant relationship between the ability to think empathically and ethnic identity (Phinney, 1996) and also with attitudes associated with the highest levels of racial identity (Steward, Boatwright, Sauer, Baden, \& Jackson, 1998). The effect of ethnic identity was also controlled by entering it on this block. Attitudes Toward Women Scale scores were entered in the third block because this was the variable that had not been examined before in the study of empathy. Interactions between the above variables were entered in the fourth block as suggested by Wampold and Freund (1987). The interaction effects entered in the fourth block included

\section{Table 3.}

Pearson product correlations between each pair of variables.

\begin{tabular}{|c|c|c|c|c|c|c|}
\hline Variable & 2 & 3 & 4 & 5 & 6 & 7 \\
\hline 1. Empathy & $.15^{\star \star}$ & .06 & $.16^{\star \star}$ & $.12^{\star}$ & $.19^{\star \star}$ & .07 \\
\hline 2. Ethnic Identity Total & & $.81^{\star \star}$ & $.89^{\star \star}$ & $.63^{\star \star}$ & -.05 & -.00 \\
\hline 3. Ethnic Identity-Affirm. & & & $.52^{\star \star}$ & $.44^{\star \star}$ & $-.17^{\star \star}$ & -.00 \\
\hline 4. Ethnic Identity-Achieve. & & & & $.40^{\star \star}$ & $.11^{*}$ & .03 \\
\hline 5. Ethnic Identity-Behavior & & & & & $-.14^{\star \star}$ & -.07 \\
\hline 6. Ethnic Identity-0ther & & & & & & $.26^{\star \star}$ \\
\hline 7. Attitudes Women Scale & & & & & & \\
\hline \multicolumn{7}{|l|}{${ }^{\star *} p<.01$} \\
\hline${ }^{*} p<.05$ & & & & & & \\
\hline
\end{tabular}


Table 4.

\section{Hierarchical Multiple Regression of Effects of Demographic variables, Ethnic Identity, and Attitudes about Women on Total Score of the Scale of Intellectual Development Empathy Subscale}

\begin{tabular}{|c|c|c|c|c|c|}
\hline Variable & R Square & $\begin{array}{l}\text { R Square } \\
\text { Change }\end{array}$ & $\begin{array}{c}\mathrm{F} \\
\text { change }\end{array}$ & Beta & $t$ \\
\hline $\begin{array}{l}\text { Block 1: Demographics } \\
\text { Gender } \\
\text { SES } \\
\text { Race }\end{array}$ & .05 & .05 & .16 & -.01 & .98 \\
\hline $\begin{array}{l}\text { Block 2: Ethnic Identity } \\
\text { Achievement } \\
\text { Behavior } \\
\text { Affirmation } \\
\text { Other }\end{array}$ & .22 & .17 & 5.37 & .23 & $2.79 *$ \\
\hline $\begin{array}{l}\text { Block 3: Attitudes about } \\
\quad \text { Women }\end{array}$ & .23 & .006 & .33 & -.30 & -1.07 \\
\hline $\begin{array}{c}\text { Block 4: Interactions } \\
\text { between } \\
\text { variables }\end{array}$ & .09 & .01 & .04 & - & - \\
\hline
\end{tabular}

Note. The overall regression model was significant, $F(10,121)=3.57, p=.0004$. For Ethnic Identify, a higher score demotes a higher level of ethnic identity or a stronger sense of cultural group identification. On attitudes about women, a higher score demotes a more liberal view of women's roles or a greater tendency to see women as being able to assume non-traditional roles. On the SID Empathy subscale, higher scores denote greater awareness of their impact on other people, a greater sensitivity about others' feeling, and a stronger sense of responsibility for improving society.

${ }^{\star} p<.001$.

demographic variables $x$ ethnic identity, demographic variables $x$ attitudes about women, and ethnic identity $x$ attitudes about women.

The overall regression model was significant for the criterion variable of empathy, $F(10,121)=3.57, p=.0004$, as noted in Table $4.23 \%$ of the variance in empathy can be explained by the variables within the whole model. The results of the multiple regression analysis showed that only one of the three independent variables, ethnic identity, was a significant predictor of the total empathy score. In predicting the tendency to think in an empathic manner, none of the interaction effects added unique predictive variance beyond what was accounted for by ethnic identity.

Neither the demographic information $(\mathrm{r}=.05)$ or Attitudes toward Women scores $(\mathrm{r}=.06)$ accounted for a significant amount of the variance among empathy scores. On the other hand, ethnic identity, which accounted for $17 \%$ of the variance, contributed significant incremental variance over demographic information. Table five presents the results of the specific contribution of each of the ethnic identity subscales to empathy. The results supported the hypothesis that students who had a stronger ethnic identity would also report greater levels of empathic thinking than those who do not.

\section{Discussion}

The goal of this study was to explore the degree to which the predictor variables of demographic information (i.e., gender, SES, race), ethnic identity, and attitudes toward women might predict college students' use of empathy. Though the whole model was found to contribute approximately $23 \%$ of the variance in the SID empathy subscale scores, only one of the three independent variable sets, ethnic identity, was found to be a significant predictor of the subscale scores (17\% of the variance).

At first glance of the results, readers might conclude that findings seem to support the multicultural theory that hypothesizes that the overall construct of ethnic identity is positively and significantly correlated with the ability to understand and connect with non-group members (Phinney, 1996; Phinney, Ferguson, \& Tate, 1997).

However, it is critical to note that only one aspect of ethnic identity, the other group orientation, was the significant predictor, which supports the social identity theory (Taifeo \& Turner, 1986). It also supports Allport's "contact hypothesis," which states that contact between groups can promote tolerance and acceptance (DeAngelis, 2001; Wang et al, 2003). These results are similar to those of previous research that established a

\section{Table 5. \\ Hierarchical Multiple Regression Results of the contribution of individual Ethnic Identity subscale scores (Affirmation, Achievement, Behavior, and Other Group Orientation) to Total Empathy Subscale Scores}

\begin{tabular}{lccc}
\hline Variable(s) & Standardized Coefficient Beta & $\dagger$ & Sig. \\
\hline 1. Affirmation & -.02 & -.17 & .87 \\
\hline 2. Achievement & .15 & 1.70 & .09 \\
\hline 3. Behavior & .12 & 1.47 & .14 \\
\hline 4. Other Group Orientation & .26 & 3.58 & .00 \\
\hline
\end{tabular}

Note. Of the four Ethnic Identity subscale scores, the only significant predictor of Empathy was found to be the Other Group Orientation subscale. 
relationship between other-group orientation and greater understanding and sensitivity (Blanchard, Crandall, Brigham, \& Vaughn, 1994; Negy, Shreve, Jensen, \& Uddin, 2003).

Four important points should be remembered as the results of this study are discussed. First, the only reason that results are interpreted and discussed with reference to black and white students is because of the representation in the sample and we do not wish to make generalizations beyond the scope of these results. The same relationship between variables may or may not be found for other groups and for other campus populations wherein the majority-minority representation is significantly different and in different geographical locations. Second, group differences in beliefs about assuming responsibility for improving society in general and for understanding personal impact on others based on race and gender may be explained in several ways. The most obvious is the limited representation of both males and blacks in this sample. Women and whites made up approximately $75 \%$ of the sample. Though some researchers' findings do not support these results (Davis, 1980, 1983, 1994; Monahan, 1989), gender differences have been found in earlier research addressing empathic thinking, with women being found to have greater empathy than men (Hatcher, 1994; Jimenez \& Abreu, 2003; Roberts \& Strayer, 1996; Sullivan, 1989; Wang et al, 2003). Male participants in this study might tend to have had more qualities that might be identified as masculine, which are not as interpersonally oriented as those qualities traditionally identified as feminine.

Significant racial differences between blacks and whites also may be interpreted in several ways. Differences in gender and race may have had a significant impact on the participants' personal experience, awareness, interpersonal functioning, and social attitudes, as indicated by previous research (e.g., Cross \& PhagtenSmith, 1996; Helms, 1995; Miville et al, 1999; Wang et al, 2003). Given that the SID measure does purport to assess levels of cognitive development and identifies the Empathy subscale as the highest form of cognitive development, some might conclude that these findings support the notion that blacks are less cognitively developed than whites. This is not the conclusion of the authors of this paper. Readers must be cautioned to revisit the operational definition of empathy as defined by this measure: sensitivity to one's impact on others and assumption of responsibility for the improvement of ased on these

results it might be

concluded that

counseling

programs' admission

of undergraduate

students from

institutions who

have provided these

experiences would

certainly increase

trainees' readiness

for graduate

education in

counseling and in

their effectiveness

as members of the

counseling

profession. society in general. SID Empathy subscale scores may be influenced by the quality of race relations within mainstream America. African Americans may be less likely to have higher empathic thinking scores due to living in a predominantly white environment wherein it might be unhealthy and unproductive to be interpersonally sensitive. Earlier studies have found that in a study of the most successful students, white students believe that they would withdraw interpersonally when in predominantly black settings (Steward, Davidson, \& Borgers, 1993), and that black university students in a predominantly white setting who feel least alienated are those who want nothing from white peers (Steward, Jackson, \& Jackson, 1990). Given this possible interpersonal dynamic, it makes sense that blacks within a predominantly white setting may not be as interpersonally sensitive as white peers in the same setting.

Black students, as members of a racial minority group, may also not feel as responsible for the improvement of society in general. Given the significant reported family annual income differences, less economically advantaged students may not only experience the powerlessness of minority group membership, but also the powerlessness which might be associated with lower socio-economic status. However, readers must also note that neither race nor family income was found to significantly contribute to the variance in participants' empathy scores. Additional research specifically examining racial differences in empathy on predominantly white campuses, and black campuses too, is certainly warranted.

Third, results of this study are subject to the limitations of any self-report survey. A sampling bias may have occurred, as no information was obtained on nonparticipants outside of these classes. Also, only attitudinal criterion variables were examined, with no behavioral indicators being included. Consequently, women and white students may overall report empathic thinking to a greater degree than men and African Americans, but in reality only engage in empathic behaviors to the same degree or less. In contrast, individuals may tend to overreport or under-report what their self-report actually reflects. Both men and African Americans may report less engagement in empathic thinking than their behavior reflects. 
Fourth, with participants in the sample being located on only one university campus in one geographical region, a generalization to students in other parts of the country may not be merited. It is also not possible to generalize the results of this study to a non-university population. The results also cannot be generalized to the unique set of undergraduate students who would pursue admission into counseling graduate programs. Future research specifically targeting this professional/academic goal would certainly add significantly to the literature.

The direct and significant predictive relationship between ethnic identity and empathic thinking, as measured by the SID, supports an earlier similar research finding linking attitudes about race and empathic thinking (Steward, Morales, Bartell, Miller, \& Weeks, 1998). In other words, the degree to which university students have a secure and positive sense of self as a member of their ethnic group in relationship to other ethnic groups (ethnic identity) is predictive of the degree that they will be sensitive to their impact on others and assume responsibility for improvement in general society (empathic thinking). Persons with insecure and negative feelings about group membership in relationship to other groups will be less likely to be socially conscious and interpersonally sensitive.

Findings suggest that efforts to enhance empathic thinking, a critical aspect of maintaining a democratic society, university programs should strategically provide and require curriculum and training experiences to include the following: increase ethnic pride, support good feelings about one's ethnic background, and support happiness with one's ethnic group membership, as well as feelings of belonging and attachment to the group (Phinney, 1992) (affirmation/belonging); guide and encourage students' exploration and resolution of past and current beliefs and attitudes that impede the development of a secure and positive ethnic identify (achievement); provide structured and unstructured social activities with members of one's ethnic group and participate in cultural traditions (ethnic behaviors); and provide structured and unstructured opportunities to specifically identify, address, and resolve negative attitudes, beliefs, and feelings toward other ethnic group members (ethnic others).

Programs might use this study as a model to assess ethnic identity, and plan and evaluate curriculum and training experiences that will facilitate the development of a secure ethnic identity even prior or simultaneously to developing general counseling competence. Providing this opportunity throughout undergraduate education might serve as the baseline experience necessary for the heightened development of cognitive empathy, the precursor of affective empathy, which is the goal of all counseling programs. Based on these results it might be concluded that counseling programs' admission of undergraduate students from institutions who have provided these experiences would certainly increase trainees' readiness for graduate education in counseling and in their effectiveness as members of the counseling profession.

Findings indicate that there is no significant relationship between individuals' attitudes about women and the degree to which one is sensitive to their impact on others or willingness to assume responsibility for the improvement of general society. Though gender-related education may inform and increase awareness and understanding of gender related issues and strengths, the findings suggest that it does not enhance the development of empathic thinking. This is a very confusing outcome given the fact that women had significantly higher empathy scores and African American students had significantly higher Attitudes toward Women scores, which is contrary to findings in earlier research (Silver, 1988). Much continued thought must be given in the interpretation of this finding so as not to encourage readers who conclude that gender is not worthy of note within the context of facilitating the development of empathic thinking.

Steward, Gimenez, and Jackson (1995) concluded that ethnicity and gender should be unique and critical components of training; however, readers must once again take note of the attitudes that are measured by the Attitudes toward Women Scale and significant correlates of such attitudes: politically liberal (Ghaffaradli-Doty \& Carlson, 1979) greater self-reported hostility (Gackenbach \& Auerback 1975); less social conformity (Johnson \& MacDonnell, 1974); inner-directedness (Hunt, 1976); goaloriented toward non-traditional vocational and educational roles (Redfering, 1979); high selfactualization (Hjell \& Butterfield, 1974; Follingstad, Kilmann, \& Robinson, 1976); assertiveness and more masculine orientation (Volgy, 1976); outspokenness, ambition, independence, competitiveness, aggressiveness, dominance, self-reliance, persistence, versatility, and willingness to challenge the laws of society (Joesting, 1976). Such descriptors are bound to be heavily culturebased. Subsequently, adoption of the feminist principles, whether defined as liberal or conservative by leading feminist researchers within mainstream academic settings, may be so tightly interwoven within the context and experience as a member of an ethnic group that the degree to which one has liberal attitudes about women becomes insignificant. This hypothesis is further supported by the absence of a significant correlation between ethnic identity and Attitudes toward Women scores. For example, "White American" being identified as an ethnic identity may mask within group diversity among whites. Some participants who identified in this manner may or may not value and embrace an unspoken 
or maybe even unknown ethnic group and associated cultural norms with values that support and encourage more conservative attitudes toward women.

The same might be true for those self identified as African American. Future researchers might be aware of the necessity to encourage participants to identify more specifically in relationship to their ethnic group membership. Researchers also might include a measure of religion and / or degree of religiosity in order to provide a more complete picture of participants' backgrounds (Arredondo et al, 1996). This might be very important, given that ethnic group and associated cultural norms typically include well-defined sex-role behaviors with which members are very familiar and comfortable, but that are in no way related to pro-feminist views.

Additional information might aid in developing a more comprehensive description of what these cultural norms are.

Nevertheless, a step has been taken to understand that which has been identified as the highest level of cognitive development among some within the profession of counseling. More specifically, findings also more clearly identify how the development of empathy among university populations might be strategically influenced. Many scholars have emphasized the importance of teaching empathic thinking at the university undergraduate level and have developed curriculum that effectively increases students' ability to do so (Gallo, 1989; Gladstein, 1983; Hatcher, 1994). Student orientation, campus program development, and faculty may be more effective in creating an overall socially responsible climate within university populations if ethnic identity is considered within the process of planning the educational experiences of our future educated populations and, in particular, our future counselors.

However, readers must also note that only $17 \%$ of the variance in the SID Empathy subscale score can be attributed to Ethnic Identity as measured by the MEIM. This outcome supports prior literature that identifies empathy as a multi-stage process that consists of multiple elements (Barrett-Lennard, 1981; Gladstein, 1983; Wang et al, 2003). Future research is certainly warranted.

\section{References}

American Psychiatric Association. (1987). Diagnostic and statistical manual of mental disorders (3rd Ed. revised). Washington, DC: Author.

American Psychological Association (2003). American Psychological Association (APA) board of directors and staff, American Psychologist editorial statement, and APA statement of purpose. American Psychologist, 58(6-7), 424.

American Psychological Association. (1995). Task force on the changing gender composition of psychology. Available: http:/ / xxx.apa.org/ pi/taskforce/homepage.html.

Arredondo, P., Toporek, R., Brown, S. P., Jones, J. (1996). Operationalization of the multicultural counseling competencies. Journal of Multicultural Counseling Development, 24(1), 42-78.

Barrett-Lennard, G.T. (1981). The empathy cycle: Refinement of a nuclear concept. Journal of Counseling Psychology, 28(4), 91-100.

Batson, C.D., Polycarpou, M.P., Harmon-Jones, E., Imhoff, H.J., Mitchener, E.C., Bednar, L.L., Klein, T.R., \& Highberger, L. (1997). Empathy and Attitudes: Can feeling for a member of a stigmatized group improve feelings toward the group? Journal of Personality and Social Psychology, 72(1), 105-118.

Berry, J.W. (1984). Multicultural policy in Canada: A social psychological analysis. Canadian Journal of Behavioural Science, 16(4), 353-370.

Blanchard, F. A., Crandall, C. S., Brigham, J. C., \& Vaughn, L. A. (1994). Condemning and condoning racism: A social context approach to interracial settings. Journal of Applied Psychology, 79(6), 993-997.

Boatswain, S., Brown, N., Fiksenbaum, L., Goldstein, L., Greenglass, E., Nadler, E., \& Pyke, S. W. (2001). Canadian feminist psychology: Where are we now? Canadian Psychology, 42(4), 276-285.

Brammer, L.M., Shostrom, E.L., \& Abrego, P.J. (1989). Therapeutic psychology: Fundamentals of counseling and psychotherapy (5th ed.). Englewood Cliffs, NJ: Prentice Hall.

Brewer, M.B. (1988). A dual process model of impression formation. In T.K. Srull \& R.S. Wyer, Jr. (Eds.), Advances in Social Cognition, 1, 1-36. Hillsdale, NJ: Erlbaum.

Broverman, I., Broverman, D., Clarkson, F., Rosenkrantz, P., \& Vogel, S. (1970). Sex-role stereotypes and clinical judgments of mental health. Journal of Consulting and Clinical Psychology, 34(4), 1-7.

Carkhuff, R.R. (1987). The art of helping (6th ed.). Amherst, MA: Human Resource Development Press.

Carter, D. B. (1990). Administration of the Personal Attributes Questionnaire, the short form of the Attitudes toward Women Scale, and the SexRole Egalitarianism Scale. Unpublished raw data, Syracuse University. Qureshi.

Chung, R. C., \& Bemak, F. (2002). The relationship of culture and empathy in cross-cultural counseling. Journal of Counseling $\mathcal{E}$ Development, 80(2), 154-159.

Cross, W., \& Phagen-Smith, P. (1996). Nigrescence and ego identity development. In P. B. Pedersen, J. G. Draguns, W. J. Lonner, \& J. E. Trimble (eds.), Counseling across cultures (pp.108-123). Thousand Oaks, CA: Sage.

Davis, M. H. (1994). Empathy: A Social Psychological Approach. Brown \& Benchmark, Madison, WS.

Davis, M. (1983). Measuring individual differences in empathy: Evidence for a multidimensional approach. Journal of Personality $\mathcal{E}$ Social Psychology, 44(1), 113-126.

Davis, M. (1980). A multidimensional approach to individual differences in empathy. JSASCatalog of Selected Documents in Psychology, 10, 85.

DeAngelis, T. (2001). Thwarting modern prejudice. Monitor on Psychology, 32(4), 134-138.

Duan, C. \& Hill, C.E. (1996). The current state of empathy research. Journal of Counseling Psychology, 43(1), 261-274. 
Egan, G. (1990). The skilled helper: Model, skills, and methods for effective helping (4th ed.). Pacific Grove, CA: Brooks/Cole.

Enns, C. Z. (1992). Toward integrating feminist psychotherapy and feminist philosophy. Professional Psychology: Research \& Practice. 23(6), 453-466.

Enns, C. Z.; Hackett, G. (1990). Comparison of feminist and nonfeminist women's reactions to variants of nonsexist and feminist counseling. Journal of Counseling Psychology. 37(1), 33-40.

Erwin, T.D. (1981). Academic status as related to the development of identity. Journal of Psychology, 111(4), 68-73.

Erwin, T.D. (1982). The scale of intellectual development using Perry's scheme. Journal of College Student Personnel, 24(6), 6-12.

Erwin, T.D. \& Delworth, U. (1980). An instrument measuring Chickering's vector of identity. National American Association of Personnel Administrators' Journal, 17(1), 19-24.

Erwin, T.D. \& Schmidt, M.R. (1981). The convergent validity of the Erwin Identity Scale. Educational and Psychological Measurement, 41(4), 1307-1310.

Farber, B.A., \& Lane, J.S. (2001). Positive regard. Psychotherapy: Theory, Research, Practice, Training, 38(4), 390-395.

Fischer, A. R.\& Good, G. E. (1994). Gender, self, and others: Perceptions of the campus environment. Journal of Counseling Psychology. 41(3), 343-355.

Follingstad, D.R., Kilmann, P.R., \& Robinson, E.A. (1976). Prediction of self-actualization in male participants in a group conducted by female leaders. Journal of Clinical Psychology, 32(4), 706-712.

Foltz, M., Kirby, P. C., \& Paradise, L. V. (1989). The influence of empathy and negative consequences on ethical decisions in counseling situations. Counselor Education E Supervision, 28(3), 219-228.

Fuertes, J.N., \& Brobst, K. (2002). Clients' ratings of counselor multicultural competency. Cultural Diversity \& Ethnic Minority Psychology, 8(3), 214-223.

Gackenbach, J.I., \& Auerbach, S.M. (1975). Empirical evidence for the phenomenon of the "well-meaning liberal male." Journal of Clinical Psychology, 31(4), 632-635.

Gallo, D. (1989). Educating for empathy, reason, and imagination. Journal of Creative Behavior, 23(3), 98-115.

Ghaffaradli-Doty, P. \& Carlson, E.R. (1979). Consistency in attitude and behavior of women with a liberated attitude toward the rights and roles of women. Sex Roles, 5(4), 395-404.

Gilbert, L. A., \& Scher, M. (1999). Gender, sex, and counseling. Boston, MA: Allyn \& Bacon.

Gladstein, G. (1983). Understanding empathy: Integrating counseling, developmental, and social psychology perspectives. Journal of Counseling Psychology, 30(4), 467-482.

Glick, P., \& Fiske, S. T. (1999). The Ambivalence toward Men Inventory: Differentiating hostile and benevolent beliefs about men. Psychology of Women Quarterly. 23(3), 519-536.

Greenberg, L.S., Watson, J.C., Elliot, R., Bohart, A.C. (2001). Empathy. Psychotherapy: Theory, Research, Practice, Training, 38(4), 380-384.

Hamilton, D.L., \& Trolier, T.K. (1986). Stereotypes and stereotyping: An overview of the cognitive approach. In J.F. Dovidio \& S.L. Gaertner (Eds.), Prejudice, discrimination, and racism: Theory and research. Orlando, FL: Academic Press.

Hammer, A. (1983). Matching perceptual predicates: Effect on perceived empathy in a counseling analog. Journal of Counseling Psychology, 30(2), 172-179.

Hatcher, S.L. (1994). The teaching of empathy for high school and college students: Testing Rogerian methods with the interpersonal reactivity index. Adolescence, 29(6), 961-974.

Helms, J. E. (1995). An update of Helms' White and people of color racial identitymodels. In J. G. Ponterotto, J. M. Casas, L. A. Suzuki, \& C. M. Alexander(eds.), Handbook of multicultural counseling (pp.181198). Thousand Oaks, CA: Sage.
Helms, J. E. (1984). Toward a theoretical explanation of the effects of race on counseling: A Black and White model. Counseling Psychologist, 12(2), 153-164.

Hjelle, L.A. \& Butterfield, R. (1974). Self actualization and women's attitudes toward their roles in contemporary society. Journal of Psychology, 87(3), 225-230.

Hoffman, M. L. (2000). Empathy and moral development: Implications for caring and justice. Cambridge University Press, Cambridge, U.K.

Honeck, S. M. (1981). An exploratory study of the Beere-King Sex-Role Egalitarianism Scale, the MacDonald Sex Role Survey, and Spence and Helmreich's Attitudes Toward Women Scale. Unpublished master's thesis, Central Michigan University.

Hunt, P.L. (1976). Female child care workers and their feminine identity congruence, attitudes toward women, self-actualization, and marital status. Doctoral Dissertation Abstracts International, 36, 4262A.

Janz, T., \& Pyke, S. W. (2000). A scale to assess student perceptions of academic climates. Canadian Journal of Higher Education, XXX(1), 89122.

Jegerski, J.A. \& Upshaw, H.S. (1987). The nature of empathy: Discriminant analyses. ERIC ED298375.

Jimenez, J. A.\& Abreu, J. M. (2003). Race and sex effects on attitudinal perceptions of acquaintance rape. Journal of Counseling Psychology, 50(2), 252-256.

Joesting, J. (1976). Personality correlates of sexism and anti-sexism in college students. College Student Journal, 10(2), 194-196.

Joffa, M. (1985). Administration of Sex-Role Egalitarianism Scale and Attitudes Toward Women Scale. Unpublished raw data, Central Michigan University.

Johnson, R.W. \& MacDonnell, J. (1974). The relationship between conformity and male and female attitudes toward women. Journal of Social Psychology, 94(2), 155-156.

Jones, R. L. (1991).Black psychology ( $3^{\text {rd }}$ ed.). Berkeley: Cobb \& Henry Publishers.

The Josephson Institute of Ethics (2002). Making ethical decisions. Marina del Rey, CA: The Josephson Institute of Ethics.

The Josephson Institute of Ethics (1992). Ethical values, attitudes, and behaviors in American schools. A report. Marina del Rey, CA: The Josephson Institute of Ethics.

Junn, E. N., Grier, L. K. \& Behrens, D. P. (2001). Playing “Sherlock Holmes": Enhancing students' understanding of prejudice and stereotyping. Teaching of Psychology, 28(2), 121-124.

Kilburg, R.R. (1997). Coaching and executive character: Core problems and basic approaches. Consulting Psychology Journal: Practice $\mathcal{E}$ Research, 49(4), 281-299.

King, L. A., \& King, D. W. (1997). Sex-role egalitarianism scale: Development, psychometric properties, and recommendations for future research.Psychology of Women Quarterly, 21(1), 71-87.

Lambert, M.J., \& Barley, D.E. (2001). Research summary on the therapeutic relationship and psychotherapy outcome. Psychotherapy: Theory, Research, Practice, Training, 38(4), 357-361.

Lee, Y. (1995). Stereotype accuracy: Toward appreciating group differences. American Psychological Association:Washington, DC.

Leonard, H.S. (1997). The many faces of character. Consulting Psychology Journal: Practice \& Research, 9(4). 235-245.

Levinson, H. (1997). Organizational character. Consulting Psychology Journal: Practice \& Research, 49(4), 246-255.

MacDonald, A. P. (1974). Identification and measurement of multidimensional attitudes toward equality between the sexes. Journal of Homosexuality, 1, 165-182.

Messick, D.M. \& Mackie, D.M. (1989). Intergroup relations. Annual Review of Psychology, 40(1), 45-81.

Miville, M.L., Gelson, C.J., Pannu, R., Liu, W., Touradji, P., Holloway, P., \& Fuertes, J. (1999). Appreciating similarities and valuing differences: The Miville-Guzman University Diversity Scale. Journal of Counseling Psychology 4 46(3), 291-307. 
Monahan, M.J. (1989). Differences in empathy: Are women really more empathic than men? ERIC ED320088.

Munley, P. H., Anderson, M. Z.; Baines, T. C., Borgman, A. L., Briggs, D., Dolan, J. P. Jr., \& Koyama, M. (2002). Personal dimensions of identity and empirical research in APA journals. Cultural Diversity \& Ethnic Minority Psychology. 8(4), 357-365.

Negy, C., Shreve, T. L., Jensen, B. J. \& Uddin, N. (2003). Ethnic Identity, Self-Esteem, and Ethnocentrism: A Study of Social Identity Versus Multicultural Theory of Development. Cultural Diversity and Ethnic Minority Psychology, 9(4), 333-344.

Okun, B.F. (1987). Effective helping: Interviewing and counseling techniques. North Scituate, MA: Duxbury Press.

Omdahl, B.L. (1995). Cognitive appraisal, emotion, and empathy. Lawrence Erlbaum Associates: Mahwah, NJ.

Orange, D.M. (2002). There is no outside: Empathy and authenticity in psychoanalytic process. Psychoanalytic Psychology, 19(4), 686-700.

Ostertag, P. A. \& McNamara, J. R. (1991). “Feminization” of psychology: The changing sex ratio and its implications for the profession. Psychology of Women Quarterly. 15(3), 349- 369.

Oswald, P.A. (1996). The effects of cognitive and affective perspective taking on empathic concern and altruistic helping. Journal of Social Psychology, 136(5), 613-623.

Parson, E.R. (1993). Ethnotherapeutic empathy (EthE)—\{Part II: Techniques in intersonal cognition and vicarious experiencing across cultures. Journal of Contemporary Psychotherapy, 23(3), 171-182.

Patrick, J.J. (1999). The concept of citizenship in education for democracy. ED432532.

Pedersen, P.B. (1990). Introduction to the special issue on multiculturalism as a fourth force in counseling. Journal of Counseling and Development, 70(4), 4.

Penn, M.L., Gaines, W., \& Phillips, H. (1993). On the desirability of owngroup preference. Journal of Black Psychology, 19(3), 303-321.

Perry, W.G., Jr. (1970). Forms of intellectual and ethical development in the college years. New York: Holt, Rinehart, and Winston.

Phinney, J.S. (1996a). Understanding ethnic diversity: The role of ethnic identity. American Behavioral Scientist, 40(2), 143-152.

Phinney, J.S. (1996b). When we talk about American ethnic groups, what do we mean? American Psychologist, 51(6), 918-927.

Phinney, J.S. (1992). The multigroup ethnic identity measure. Journal of Adolescent Research, 7(2), 156-176.

Phinney, J. S., Ferguson, D. L., \& Tate, J. D. (1997). Intergroup attitudes among ethnic minority adolescents: A causal model. Child Development, 68(5), 955-969.

Ponterotto, J.G., Gretchen, D., Utsey, S. O., Stracuzzi, T., \& Saya, Jr., R. (2003). The multigroup ethnic identity measure (MEIM): Psychometric review and further validity testing. Educational and Psychological Measurement, 63(4), 502-515.

Pratto, F., Sidanius, J., Stallworth, L.M. \& Malle, B.F. (1994). Social dominance orientation: A personality variable predicting social and political attitudes. Journal of Personality and Social Psychology, 67(4), 741-763.

Quintana, S. M., CastaÒeda-English, P., \& Ybarra, V.C. (1999). Role of perspective-taking abilities and ethnic socialization in development of adolescent ethnic identity. Journal of Research on Adolescence, 9(2), 161-184.

Redfering, D.L. (1979). Relationship between attitudes toward feminism and levels of dogmatism, achievement, and anxiety. Journal of Psychology, 101(3), 297-304

Reid, P. Trotman (2002). Multicultural psychology: Bringing together gender and ethnicity. Cultural Diversity \& Ethnic Minority Psychology. $8(2), 103-114$

Ridley, C.R., \& Lingle, D.W. (1996). Cultural empathy in multicultural counseling: A multidimensional process model. In P. Pedersen, J. Drugans, W. Lonner, \& J. Trimble (Eds.). Counseling across cultures
( $4^{\text {th }}$ Ed.), pp. 2-46. Newbury, CA: Sage.

Ridley, C.R., \& Udippi, S. (2002). Putting cultural empathy into practice. In P. Pedersen, J. Drugans, W. Lonner, \& J. Trimble (Eds.). Counseling across cultures ( ${ }^{\text {th }}$ Ed.), pp. 317-333 Thousand Oaks, CA: Sage..

Roberts, W. \& Strayer, J. (1996). Empathy, emotional expressiveness, and prosocial behavior. Child Development, 67(4), 449-470.

Rogers, C.R. (1942). Counseling and psychotherapy. Boston: Houghton Mifflin Company.

Scott, N.E., \& Borodovsky, L.G. (1990). Effective use of cultural roletaking. Professional Psychology Research \& Practice, 21(3), 167-170.

Silver, N. (1988). Attitudes toward women among Black and White university students. ERIC ED298401.

Smith, R.L. \& Bradley, D.W. (1980). In defense of the attitudes toward women scale: An affirmation of validity and reliability. Psychological Report, 47(4), 511-522.

Spence, J.T. \& Helmreich, R., \& Stapp, J. (1973). A short version of the Attitudes toward Women Scale (AWS). Psychonomic Bulletin, 2(2), 219-220.

Spence, J. T., Helmreich, R. L., \& Stapp, J. (1974). The Personal Attributes Questionnaire: A Measure of sex-role stereotypes and masculinityfemininity. JSAS Catalog of Selected Documents in Psychology, 4(1), 4344 (Ms. 617).

Spence, J.T. \& Helmreich, R. (1972). The Attitudes Toward Women Scale: An objective instrument to measure attitudes toward the rights and roles of women in contemporary society. Journal Supplement Abstract Service, 2(1), 66.

Steward, R.J., Boatwright, K.J., Sauer, E., Baden, A., Jackson, J.D. (1998). The relationships among counselor-trainees' gender, cognitive development, and White racial identity status: Implications for counselor training. Journal of Multicultural Counseling $\mathcal{E}$ Development, 26(3), 254-272.

Steward, R.J., Davidson, J., \& Borgers, S. (1993). Racial majority vs. minority status: A study of interactional styles of successful White students on a predominantly White university campus. Journal of College Student Development, 34(3), 295-299 .

Steward, R.J., Gimenez, M.M., \& Jackson, J.D. (1995). A study of personal preferences of successful university students as related to race/ethnicity, and sex: Implications and recommendations for training, practice, and future research. Journal of College Student Development, 36(2), 123-131.

Steward, R.J., Jackson, J., \& Jackson, J. (1990). Black students' interpersonal style in a predominantly white environment: Who feels alienated? Journal of College Student Development, 31(4), 509-515.

Steward, R.J., Morales, P.C., Bartell, P.A. Miller, M., \& Weeks, D. (1998). The multiculturally responsive versus the multiculturally reactive: A study of perceptions of counselor trainees. Journal of Multicultural Counseling and Development, 26(1), 13-27.

Struch, N., \& Schwartz, S.H. (1989). Intergroup aggression: Its predictors and distinctness from in-group bias. Journal of Personality $\mathcal{E}$ Social Psychology, 56(3), 364-373.

Sullivan, L.A. (1989). Empathy and social skills as predictors of social support. ERIC ED310328.

Szymanski, D. M.,Baird, M. K., \& Kornman, C. L. (2002). The feminist male therapist: Attitudes and practices for the 21st century. Psychology of Men \& Masculinity, 3(1), 22-27.

Tajfel, H. (1986). The social identity theory of intergroup behavior. In S. Worshel \& W.G. Austin (Eds.) Psychology of Intergroup Relations. Chicago, IL: Nelson Hall.

Thomas, K. R., \& Weinrach, S. G. (2004). Mental Health Counseling and the AMCD Multicultural Counseling Competencies: A Civil Debate. Journal of Mental Health Counseling, 26(1), 41-43.

Thomas, K. R., \& Weinrach, S. G. (1999). Multiculturalism in counselling and applied psychology: A critical perspective. Educational \& Child Psychology, 76(4), 70-83. 
Thomas, K. R., \& Weinrach, S. G. (2002a). Racial bias in rehabilitation: Multiple interpretations of the same data. Rehabilitation Education, 16(1), 81-90.

Thomas, K. R., \& Weinrach, S. G. (2002b). Solution-focused versus problem-focused rehabilitation counseling research: Is there a racist, sinner, or apostate hiding under the bed? Rehabilitation Education, 16(3), 313-321.

Tzeng, O.C. \& Jackson, J.W. (1994). Effects of contact, conflict, and social identity on interethnic group hostilities. International Journal of Intercultural Relations, 18(2), 259-276.

Volgy, S.S. (1976). Sex-role orientation and measures of psychological well-being among feminists, housewives, and working women. Dissertation Abstracts International, 37, 533B.

Wampold, D.W., \& Freund, R.D. (1987). Use of multiple regression in counseling psychology research: A flexible data analytic strategy. Journal of Counseling Psychology, 34(3), 372-382.
Wang, Y., Davidson, M., Yakushko, O. F., Savoy, H. B., Tan, J. A., \& Bleier, J. K. (2003). The Scale of Ethnocultural Empathy: Development, validation, and reliability. Journal of Counseling Psychology. 50(2), 221-234.

Weinrach, S. G., \& Thomas, K. R. (2004). The AMCD Multicultural Counseling Competencies: A Critically Flawed Initiative. Journal of Mental Health Counseling, 26(1), 81-93.

Weinrach, S. G., \& Thomas, K. R. (2002). A critical analysis of the multicultural counseling competencies: Implications for the practice of mental health counseling. Journal of Mental Health Counseling, 24(1), 20-35.

Weinrach, S. G., \& Thomas, K. R. (1998). Diversity-sensitive counseling today: A postmodern clash of values. Journal of Counseling $\mathcal{E}$ Development, 76(1), 115-122.

Weitz, H. (1957). Counseling as a function of the counselor's personality. Personnel and Guidance Journal, 35(3), 276-280.

Worell, J., \& Remer, P. (2003). Feminist perspectives in therapy: Empowering diverse women. Hoboken, NJ: Wiley. 